\title{
CHARACTERISTICS OF TOMATO SEEDS GERMINATION UNDER THE INFLUENCE OF MICROBIAL PREPARATIONS BACTOPASLON
}

\author{
Yevtushenko T. A. \\ Institute of Agricultural Microbiology and Agroindustrial Manufacture, NAAS, \\ Chernihiv \\ 97, Shevchenko str., Chernihiv, 14027 \\ E-mail: tatianazherebor@rambler.ru
}

Positive influence of Bactopaslon on the tomato seeds germination rates was observed. It was shown that application of microbial preparation improves seeds germination $10 \%$ to $25 \%$, germination rates - from $19 \%$ to $36 \%$, germination evenness - from $2 \%$ to $6 \%$, speed of seeds germination - from $29 \%$ to $64 \%$ and weight of seedlings - from $45 \%$ to $113 \%$.

Keywords: Bactopaslon, tomatoes, seeds germination, germination rates, seeds germination evenness, speed of seeds germination, weight of seedlings.

Germination of seeds is the most vulnerable stage of plants development characterized with the minimal plants resistance to various adverse factors [1]. Thus, it is relevant to study the effect of microbial preparations on the germination of tomato seeds. In order to increase the efficiency of microbial preparations action, it is perspective to the use plant lectins in the technologies of their production. However, due to the very low output of tomato lectin, its use in the manufacture of microbial preparations increases a lot their cost. By its physic-chemical and biological properties and interaction with carbohydrates and glucoconjugates tomato lectin is similar to potato lectin, which is much more accessible and cheaper. In addition, the structure of tomato lectin is similar to the lectins structure of Solanaceae family plants [2]. Thus, we developed a microbial preparation Bactopaslon based on consortium of Azotobacter vinelandii and Azotobacter chroococcum strains, cultivated with potato lectin, which effectiveness was proven in our previous work on potato cultivation technology [3].

Taking that into the account, the purpose of given research was to study the effect Bactopaslon on tomatoes seed germination of different maturity groups.

Materials and methods. Microbial preparation Bactopaslon, based on the consortium of bacterial strains Azotobacter chroococcum and Azotobacter vinelandii [4], cultivated with potato lectin was used. Influence of Bactopaslon on seed germination of was investigated on tomato plants of Flora, Rozheviy gigant and Slavskii rozheviy varieties in laboratory conditions. As positive control, we used the biological preparation Azotobakteryn recommended for application in cultivation techniques of vegetable crops [5].

The influence of microbial preparations on the germination of tomatoes, energy, seedling vigor, speed of germination and seedling mass was determined by conventional methods $[6,7]$. Seeds of tomatoes were grown in Petri dishes on filter paper previously moistened with sterile tap water, treated with microbial preparations, diluted with water at 1:100 ratio. The following experimental scheme was used: 1) control (seeds treated with water); 2) seeds treatment with 
Azotobakteryn; 3) seeds treatment Bactopaslon. Repetition of experiments - three fold. Seeds were grown in incubator at $25^{\circ} \mathrm{C}$. The evaluation of studied parameters of seeds germination was performed on a daily basis.

The data obtained was used for variation statistics analysis using the software package «Excel $-2010 »$ and «Statistica $6.0 »$, difference probability was determined using Student t-test [8].

Results and discussion. Germination and germinating rate are a key indicators of seeds quality, affecting the productivity of crops $[1,6]$. Seeds germination - its ability to form well -developed seedlings is differentiate on laboratory (germination in the laboratory conditions ensuring proper germination of most of the analyzed seeds) and field (in field conditions).

Treatment of tomato seeds with Bactopaslon had ensured the highest germination rates in laboratory tests. The germination rates in this variant had exceeded the control values in tomato varieties Flora on $17 \%$, Rozheviy gigant - on $25 \%$ Slavskii rozheviy - on $10 \%$ (Fig. 1). At this, the increase of studied parameters in variants with seeds treatment with Azotobakteryn had exceeded the control values on $10 \%, 18 \%$ and $7 \%$, respectively.

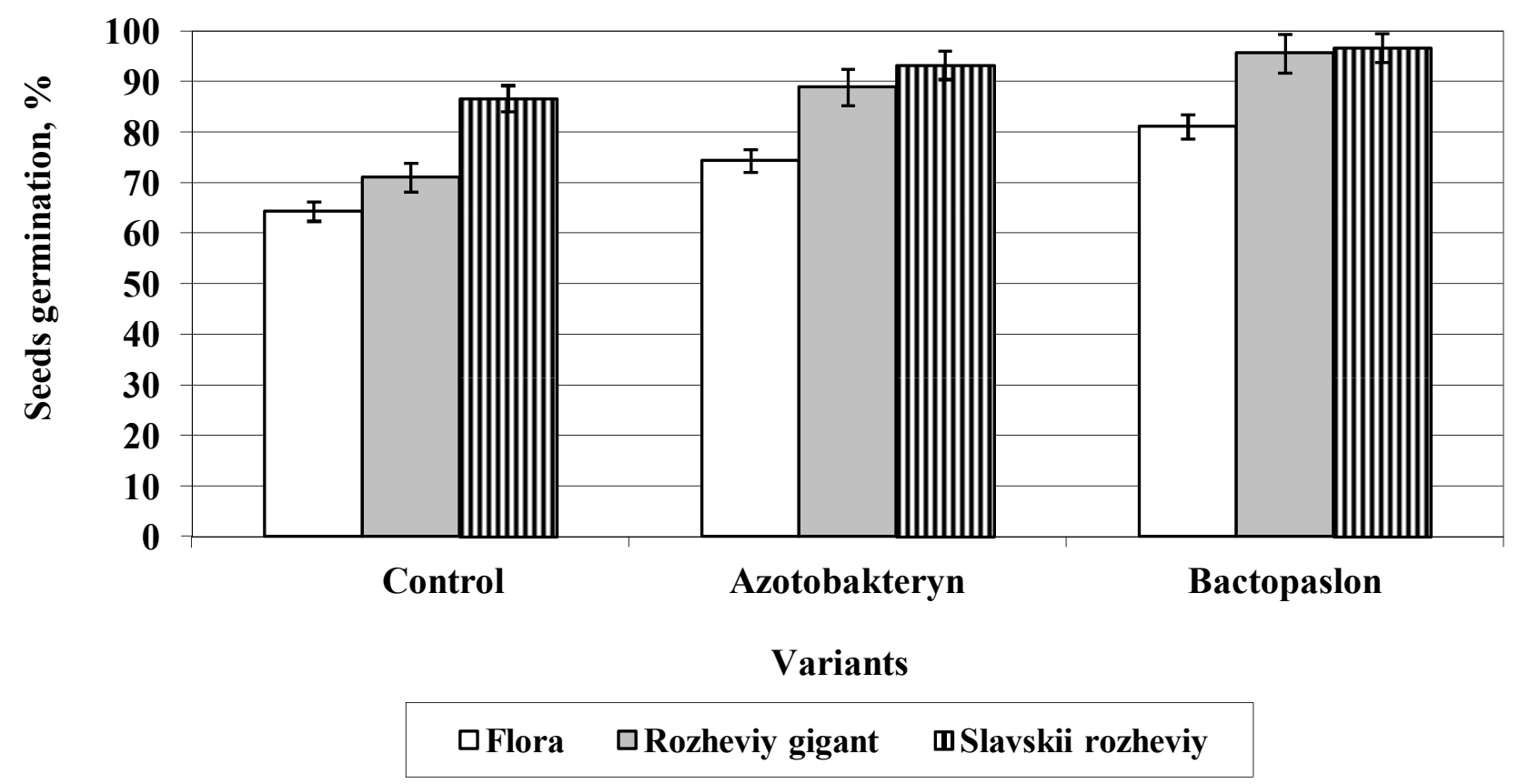

FIGURE 1. Influence of microbial preparations on germination of tomato seeds

Along with laboratory germination, the seeds germinating energy was determined - sprouting ability for rapid germination and seedling vigor that characterizes seeds viability [7]. High germinating energy foresees that the seedlings are strong and resistant to adverse environmental conditions during sowing and emerging [1]. Numerous studies have shown that seeds with higher germinating energy have better seedling vigor and evenness, while seeds with the same germination, but with low germinating energy values. Field germination of seeds with low germination energy is decreasing more intensively: field germination period is increasing, which in turn increases the risk of plant damage with fungal diseases and pests [9]. 
It was established that the energy of tomato seeds germination had significantly increased in the variants with microbial preparation use. Thus, Azotobakteryn had increased the germination energy of tomato seeds of Flora variety on $10 \%$ in compared to control, on $16 \%$ - in Rozheviy gigant variety, and on $20 \%$ in Slavskii rozheviy variety (Fig. 2). Bactopaslon appear to be more effective. In variants with seeds treatment with Bactopaslon the germination energy of tomato seeds of studied varieties had increased on $19 \%, 22 \%$ and $36 \%$, correspondingly, if compared to control.

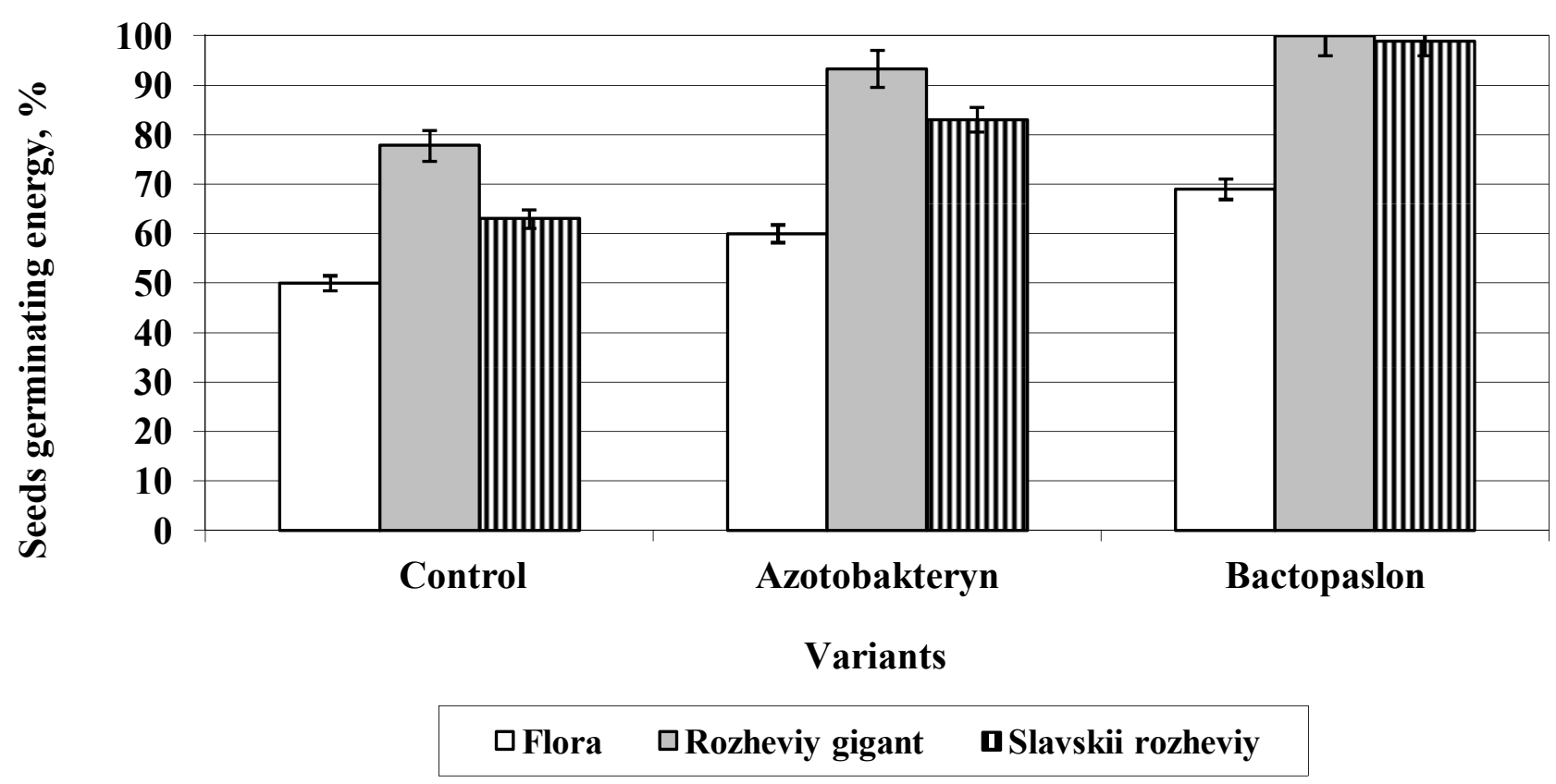

FIGURE 2. Influence of microbial preparation on germination energy of tomato seeds

The positive impact of studied microbial preparations on germination and germinating energy of tomato seeds can be explained by the ability of bio-agents (bacteria of the genus Azotobacter) to synthesis of plant hormones, since hormones and hormone-like substances are interaction mediators between plants and microorganisms [10]. Free living diazotrophs of Azotobacter genus are characterized by their ability to accumulate high amount of hormones of auxin and cytokinin nature in the culture medium (up to $200 \mathrm{mkg} / \mathrm{dm}^{3}$ ) $[11,12]$.

Phytohormonal compounds synthesized by Azotobacter can play an important role in the exchange of metabolic products between plants and bacteria, that positively affects the ryzoplan colonization with soil microflora and, respectively, plants growth processes in (due to changes in the plant hormonal pool, and the ratio of auxin and cytokinin in tissues) [11].

Germinating energy and laboratory germination are often correspond in quantitative analysis, so in order to have more differentiated seeds characteristics the germination rate, seedlings vigor and growth strength are used as additional parameters. Germination rate shows the average duration of one seed germination (in days), while the seedlings vigor - the average number of seeds that sprouted per day. 
As it was shown bacterial preparations also had a positive effect on seedlings vigor of tomato seeds. Thus, the most sensitive to the action of biological products was tomato seeds of Rozheviy gigant variety. Treatment with Azotobakteryn had promoted increase of seedlings vigor on $4 \%$, if compared to control, while application of Bactopaslon - on $6 \%$ (Fig. 3).

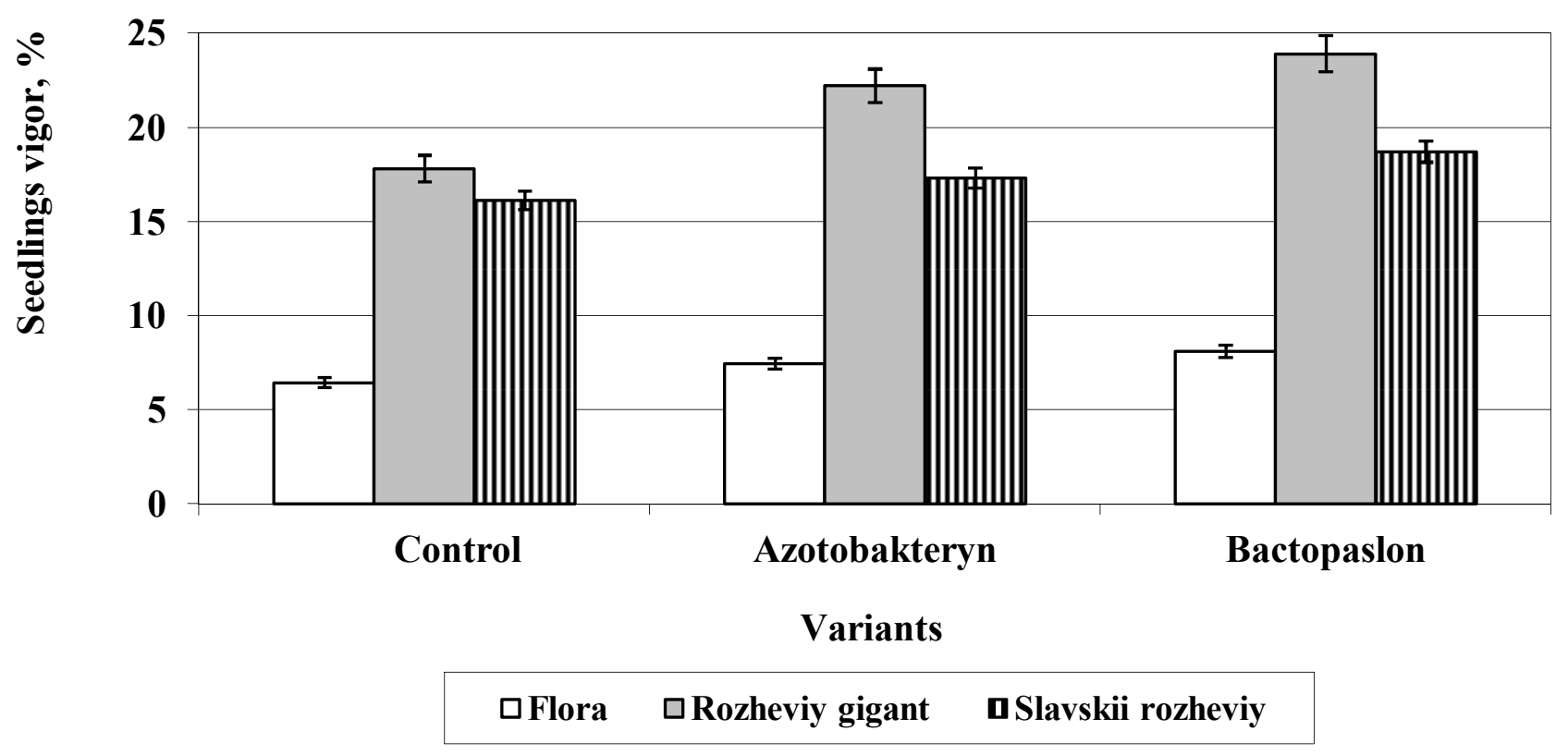

FIGURE 3. Influence of microbial preparations on the seedlings vigor of tomato seeds

The positive effect of microbial preparations on seedlings vigor was also observed experiments with other tomato varieties, but those values were within the error of experiment range.

The rate of seed germination had also increased under the influence of microbial preparations. Thus, treatment of tomato seeds with Azotobakteryn had increased the rate of seeds germination in comparison to control in Flora variety on $19 \%$, and on $27 \%$ in varieties Rozheviy gigant and Slavskii rozheviy (Fig. 4). Application of Bactopaslon had stimulated the rate of seeds germination on $29 \%, 43 \%$ and $64 \%$, respectively. It should be noted that treatment of seeds with Bactopaslon had boosted the germination rate if compared to Azotobakteryn on 8\% for Flora variety, on 12\% for variety Rozheviy gigant and on $29 \%$ for variety Slavskii rozheviy.

The ability to form normal seed sprouts in field conditions promote emerging and develop into productive plants, or the growth strength of seeds, is the another additional parameter used for determination of seeds quality in the laboratory. Seeds growth strength has a high correlation with field germination and is characterized by two parameters: the number and weight of shoots that appear over a certain period of seeds germination. 


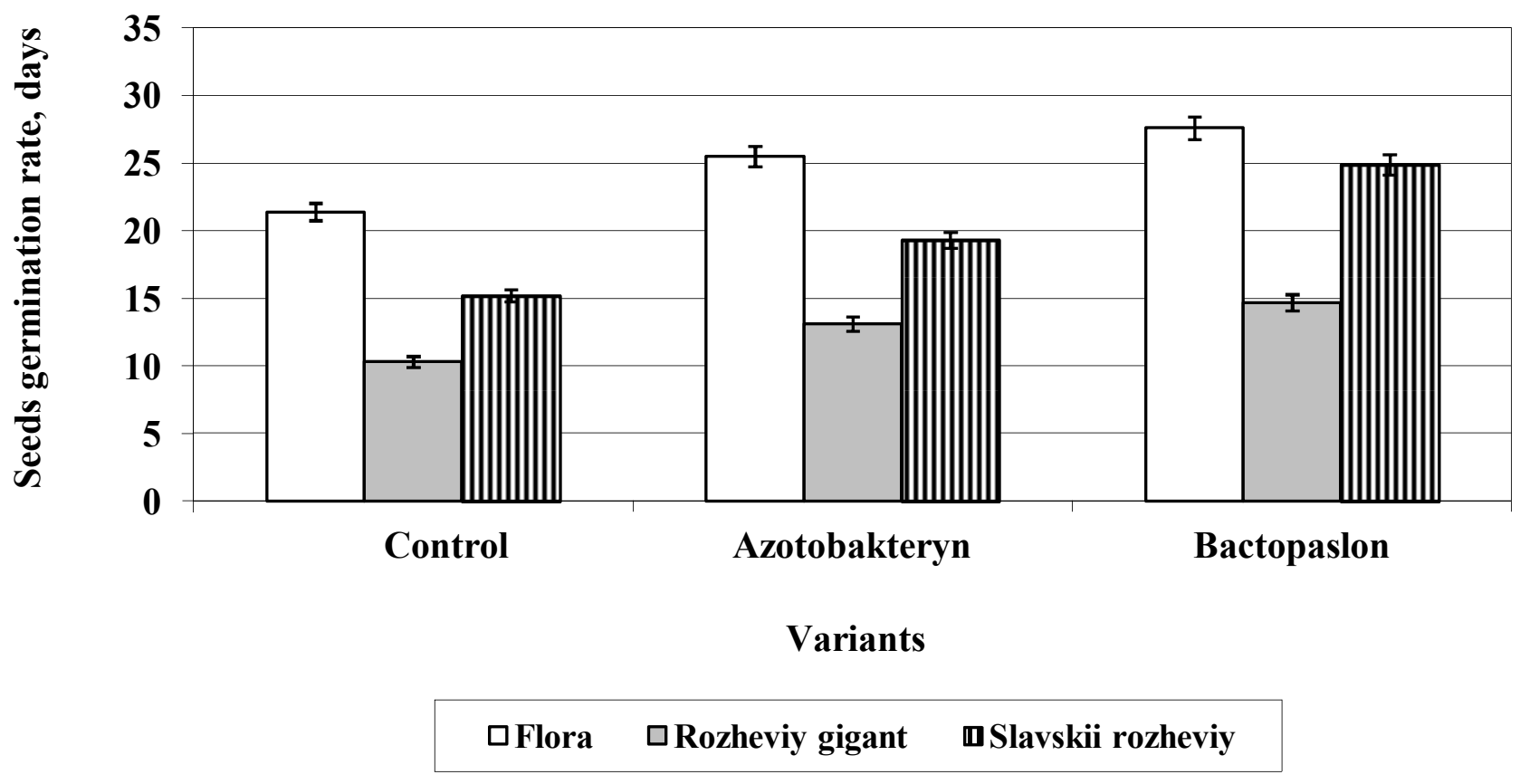

FIGURE 4. Influence of microbial preparations on the germination rate of tomato seeds

Our results had shown that microbial preparations have a positive effect on the formation of tomato seedlings due to the significant increase of their green weight in comparison with the control variant. It should be noted, that treatment of seeds of all varieties with Bactopaslon had significantly increased those values. Figure 5 shows that tomato seedlings of Flora variety had formed higher biomass in the variants with Bactopaslon treatment which exceeded the control values on $45 \%$, while Azotobakteryn aplication had promoted biomass accumulatioon on $30 \%$.

A similar dependence was observed also for the tomato of Rozheviy gigant variety: biomass of seedlings in the variants with Bactopaslon was $62 \%$ higher than in controls and $24 \%$ higher if compared with seedlings biomass in the variants with Azotobakteryn.

It should be noted that the most significant biological effect on seedlings formation was observed in tomatoes of Slavskii rozheviy variety. The studied parameter in the variants with Bactopaslon application was two times higher if compared to the control and exceeded Azotobakteryn effect on 47\%.

The data presented indicate that Bactopaslon had influenced the germination of tomato seeds in a greater extent than Azotobakteryn, which is quite obvious, since add-on of the potato lectin had stimulated the synthesis of Azotobacter substances of auxin and cytokinin nature [13].

Thus, it was established that microbial preparation Bactopaslon had increased germination of tomato seeds, its germinating energy, seedlings vigor, germination rates and seedling weight, indicating the possibility of implementation of this microbial preparation into the growing technology of tomato plants. 


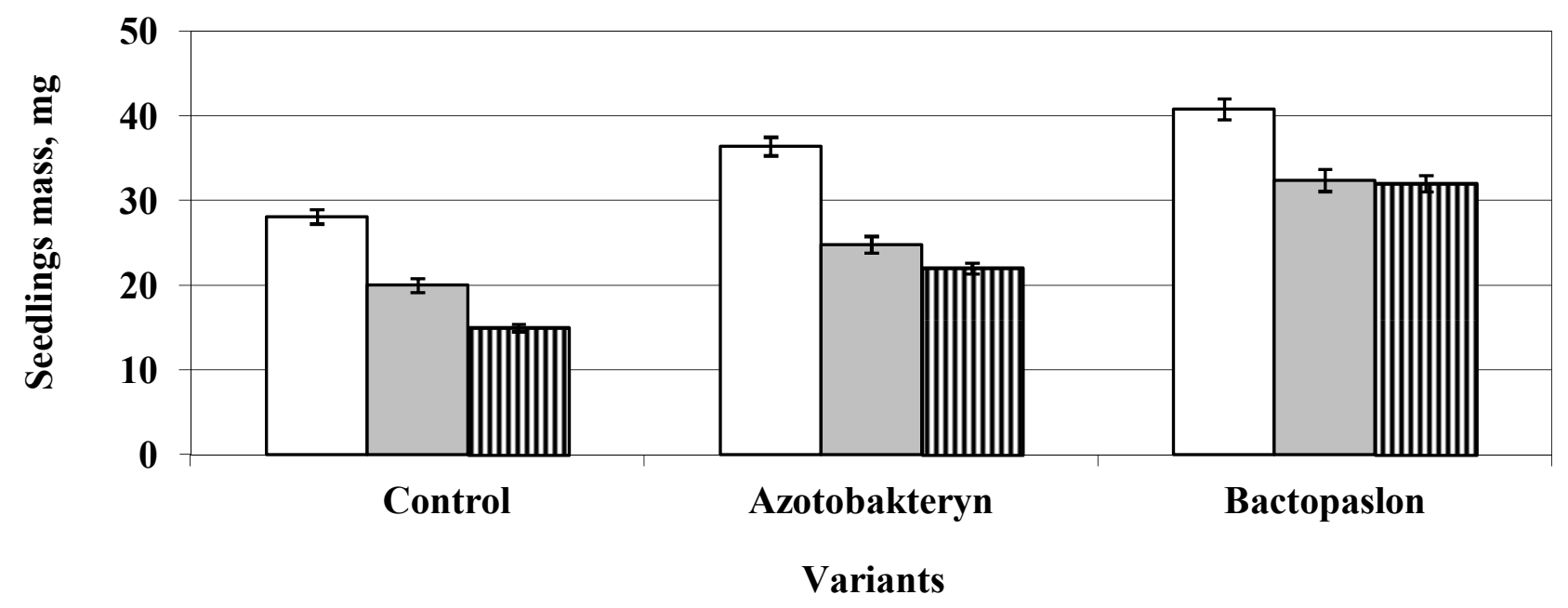

$\square$ Flora $\square$ Rozheviy gigant $\quad$ SSlavskii rozheviy

FIGURE 5. Influence of microbial preparations on the biomass accumulation of tomato seedlings 